\title{
Jovens delinquentes e universitários agressivos: diferenças comportamentais
}

\author{
FeminoFemandes Sisto- UniversidadeSão Francisco, Itatiba, SãoPaulo, Brasil \\ FemandoJoséSilvera - UnivesidadeSãoFranisco, Itatiba, SãoPaulo, Brasil \\ DarioCeilioFemandes - UnivesidadeSãoFraniso, Itatiba, SãoPaulo, Brasil
}

\begin{abstract}
Resumo
Este artigo teve como objetivo verificar as diferenças de condutas agressivas entre um grupo de pessoas que cometeram delitos (grupo 1) e um grupo de universitários com as maiores pontuações na Escala de Avaliação de Tendência a Agressividade (grupo 2). 0 grupo 1 foi constituído por 41 jovens com idades entre 18 e 19 anos, enquanto o grupo 2 foi composto por 42 participantes universitários com idades entre 18-29 anos. Os resultados mostraram 0 grupo 1 caracterizou-se por condutas relacionadas a enganar para prejudicar, obter sexo ou não perceberem minha culpa; desafiar pessoas, descarregar a raiva em alguém e andar armado, enquanto o grupo 2 apresentou apenas o fato falar alto quando não atendido ou entendido.
\end{abstract}

Palavasdhave Agressividade; D elinquência; Universitários.

\section{Deliquent juvenile and aggressive college student: behavioral differences}

\begin{abstract}
This article aims to verify the differences in aggressive behaviors in a group of people who committed crimes (group 1) and a group of college students with the highest scores on the Escala de Avaliação de Tendência a Agressividade (group 2). Group 1 consisted of 41 18-19 years persons, while Group 2 was composed of 42 18-29 year-old participating students. The results showed that group 1 was characterized by conduct related to injury, sex, or it is not my fault; defying people, raging at someone and carrying a gun. Group 2 showed only the fact "speak loud" when misunderstood.

Keguards Aggression; Delinquency; College students.
\end{abstract}

Jóvenes delincuentes y universitarios agresivos: diferencias comportamentales

\begin{abstract}
Resumen
Este artículo tiene como objetivo verificar las diferencias de conductas agresivas entre un grupo de personas que cometieron delitos (grupo 1) y un grupo de universitarios con los más altos puntajes en la Escala de Avaliação de Tendência a Agressividade (grupo 2). El grupo fue compuesto por 41 jóvenes de edades comprendidas entre 18 y 19 años, mientras que el grupo 2 fue compuesto por 42 universitarios de edades entre 18-29 años. Los resultados mostraron que el grupo 1 se caracterizó por conductas relacionadas a engañar para perjudicar, tener sexo, o no darse cuenta de mi culpa; desafiar a la gente; descargar la ira en alguien y estar armado, mientras que el grupo 2 presentó solamente el facto de hablar alto cuando no atendidos o entendidos.

Palabras dave Agresividad; D elincuencia; Universitarios.
\end{abstract}

A agressividade pode ser confundida com o termo violência. Muitos estudos salientam similitudes entre os dois termos, chegando por vezes a utilizá-los como se tratasse de um mesmo fenômeno (Grisci, 1991; Sisto, 2003; Spósito, 2001; dentre outros). Como a maioria dos fenômenos humanos, as causas da agressão são múltiplas.

A esse respeito, pesquisas procuraram verificar quais fatores (biológico, ambiental, psicológico e social) influenciariam o comportamento agressivo. É provável que algumas pessoas recorram à violência por causa de uma forte predisposição genética ou por um problema neurológico. Dentre as causas orgânicas, já foram apontados como culpados a testosterona e a serotonina, por exemplo. 0 primeiro explicaria porque os homens, histórica e independentemente da cultura em que foram criados, são mais agressivos do que mulheres (Lippa, 1990). O segundo, porque os níveis desse neurotransmissor estão associados negativamente com a agressão e a impulsividade (Lipsitt, 1990), ainda que nem todas as pessoas com baixos níveis sejam violentas, pois o ambiente pode incitar, desenvolver, inibir ou ensinar como controlar o comportamento agressivo (Myers, 1993). Entretanto, outros respondem agressivamente quando frustrados e outros aprenderam que podem conseguir o que querem assaltando uma pessoa (Anderson \& Bushman, 2002).

Segundo Patterson, DeBaryshe e Ramsey (1989) e Huesmann e Guerra (1997), o comportamento agressivo futuro teria relações com crenças familiares, bem como com a obtenção de sucesso por meio de comportamentos agressivos. Berkowitz (1990) e Geen (2001) indicaram que essa disposição negativa estaria associada a um afeto negativo, intermediando a agressão e a exposição do indivíduo às circunstâncias frustrantes ou provocativas. Toda essa disposição poderia ser potencializada pela provocação, constatada como uma das causas mais evidentes de comportamentos agressivos no ser humano (Berkowitz, 1993; Geen, 2001). As respostas a esses estímulos seriam não apenas a agressão física, como também a agressão verbal e formas de atrapalhar uma pessoa em sua tentativa de alcançar um objetivo. 
Em contraposiçäo, diferentemente das intluëncias contextuais e orgânicas, outra tendência à agressividade está relacionada com a autoestima, discutida por Baumeister, Smart e Boden (1996), Bushman e Baumeister (1998) e Kernis, Grannemann e Barclay (1989). Os autores relataram que a elevação da autoestima produziria influência elevada na agressão. Assim, pessoas com autoestima elevada ou até mesmo instável estariam mais propensas a experiências de raiva, resultando em condutas agressivas quando sua autoimagem fosse ameaçada.

Ao lado disso, outras evidências internas do indivíduo também parecem potencializar comportamentos agressivos. Para Sisto (2010), o estado interno da pessoa determinaria, em grande parte, o tipo de inferência a ser feita em uma determinada situação. Avaliações imediatas e não planejadas estão associadas a uma informação afetiva, a um objetivo e a uma intenção. A resposta agressiva que a pessoa emite pode relacionar-se com seu histórico de aprendizagem social, sua personalidade e seu estado mental no momento.

Em contraposição, algumas teorias sociológicas defenderam a adolescência como período de estruturação emocional, inferindo que os atos extremos de agressividade dos jovens, como os observados na delinquência, poderiam ser vistos como uma externalização das emoções dos adolescentes em resposta às demandas de uma cultura adulta dominante (Sisto, 2010). A esse respeito, Krueger e cols. (1994), em um estudo com um grupo de delinquentes de 18 anos, evidenciou a impulsividade juntamente com 0 prazer desses jovens pelo perigo e a rejeição dos valores socialmente convencionais. As altas pontuações nas escalas utilizadas avaliaram presença de alienação, ansiedade, agressão, contrapondo o baixo controle e proximidade social. Nessa direção, Pearlin, Menaghan, Lieberman e Mullan, (1981) caracterizaram o comportamento do delinquente como uma adaptação provisória ao estresse associado ao desenvolvimento característico da adolescência, mas ao mesmo tempo um estressor.

Os traços emocionais associados à agressividade podem ser encontrados nas pesquisas realizadas por Krueger e cols. (1994). Esses autores selecionaram grupos extremos com sensibilidade à provocação e suscetibilidade emocional (tendência à aflição) e estudaram a tendência agressiva desse grupo com ou sem provocação. Os resultados mostraram que as pessoas altamente irritáveis apresentaram maior agressividade que as menos irritáveis depois da provocação. A alta emotividade negativa deixaria a pessoa mais propensa a interpretar eventos como aversivos, manifestando condutas agressivas e antissociais como respostas a esses eventos. Esses autores acrescentaram também que essas pessoas frequentemente forneceram habilidades limitadas na resolução de problemas. Assim, determinados traços de personalidade predisporiam as pessoas a altos níveis da agressão e estariam associados a uma maior suscetibilidade para a atribuição causal hostil, vieses de percepção e expectativa (Dill, Anderson, Anderson \& D euser, 1997; entre outros).

Psicólogos clínicos e pesquisadores consideraram a agressão uma característica proeminente da personalidade, evidenciada em estudos que apontam-na agressão como um traço estável e, quando manifestada precocemente, poderia indicar a possibilidade de um comportamento criminoso na vida adulta (Huesmann, Eron \& Dubow, 2002; por exemplo). Para Lish, Kavoussi e Coccaro (1996), dentre outros, a agressividade, em situações mais graves, pode ser considerada como um dos traços de personalidade inclusos, muitas vezes, no domínio da psicopatologia, com variações nos seus níveis.

No que tange aos jovens delinquentes percebe-se que determinados traços de personalidade associados a vulnerabilidades contextuais desencadeiam vieses de comportamentos (Dill \& cols., 1997; entre outros). Ao mesmo tempo, é necessário considerar que, em geral, os atos agressivos incomodam e podem produzir raiva na pessoa agredida, ou até em quem observa a agressão.

Em relação aos aspectos antissociais e prossociais da personalidade de homens de risco, Gomà-iFreixanet (1995) estudou as características típicas de criminosos antissociais, com históricos de delito. 0 autor concluiu que os traços mais evidentes nesses sujeitos foram desinibição, psicoticismo, impulsividade, neuroticismo e baixa socialização. Segundo esse mesmo autor, os homens verbalizavam indícios de sensação impulsiva e ações não aceitas socialmente.

Essas atitudes podem ser vistas relatadas em Krueger e cols. (1994) e Gomà-i-Freixanet (1995) de forma diferente entre os dois sexos, ressaltando a impulsividade, uma emotividade negativa ao baixo autocontrole e à falta de contatos sociais. Nos trabalhos desenvolvidos por esses autores com indivíduos de ambos os sexos, os homens apresentaram resultados mais favoráveis à ansiedade e à hostilidade e mostraram pontuações baixas em inibição de agressão e desejabilidade social, além de traços de personalidade relacionados a psicopatias. No que se refere ao grupo do sexo feminino, as pontuações altas foram mais evidenciadas na ansiedade cognitivossocial e menos evidentes nos sentimentos de consciência de culpa, além de emocionalidade negativa. Essas pesquisas indicaram que o aumento da agressividade do 
criminoso pode ter viés com o planejamento e controle do impulso.

Ao lado disso, em relação aos comportamentos específicos observados em criminosos e criminosas, Pulkkinen, Virtanen, Klinteberg e Magnusson (2000) estudaram dados que evidenciaram comportamentos diferenciados para homens e mulheres. No que concerne ao sexo masculino, os delinquentes com tendência etílica mostraram maior intensidade no traço de personalidade de psicopatia, além de alta impulsividade e baixa socialibilidade. Raine (1993) e Raine, Reynolds, Venables, Mednick \& Farrington (1998) afirmaram que dentre os processos psicológicos que conduzem a atos arriscados e antissociais encontram-se a falta de medo, o temperamento desinibido, a subestimulação pessoal e a procura por estimulação e perigo.

Estudos como os de Check, Malamuth, Elias e Barton (1985) e Lisak e Roth (1990), por exemplo, informaram sobre perfis da personalidade de universitários estupradores com base em autorrelatos. Os resultados apontaram características relacionadas a ausência da empatia, hostilidade ligada aos aspectos masculinos, impulsividade, personalidades dominantes e controladoras, sentimentos de poder para com as mulheres e, finalmente, a raiva.

Há também uma associação entre criminalidade e abuso de álcool, pois pessoas que cometeram muitos crimes tenderam a beber muito também (Virkkunen \& Linnoila, 1993). O estudo de Murdoch, Pihl e Ross (1990) mostrou que em 50\% de todos os crimes violentos foi constatada intoxicação por álcool, colocando 0 seu uso como co-partícipe da criminalidade. A esse respeito, em uma boa parte dos crimes violentos, tanto o agressor quanto 0 agredido ingeriram álcool, principalmente quando a vítima era do sexo masculino (Murdoch \& cols., 1990).

Jovens universitários com contexto social e cultural diferenciado também podem apresentar comportamentos agressivos. Lippa (1990) e Myers (1993) descreveram causas físicas vinculadas a mecanismos orgânicos independentemente da cultura em que os indivíduos foram criados, apesar de que 0 ambiente pode ensinar como controlar 0 comportamento agressivo, mas também estimular, desenvolver ou refrear manifestações agressivas. Essa ideia reforça, no entanto, a natureza do quanto 0 ambiente seria fator mediador da agressão e, em consequência, nenhum seria capaz de explicar por si só a agressividade humana.

O utras pesquisas desenvolvidas utilizando jovens agressivos regidos por condutas antissociais apresentaram em seus resultados relações com histórico de dificuldades em expressar opiniões ou colocar seus objetivos perante o grupo, como também com limitações na capacidade intelectual. Relataram ainda dificuldade para estabelecer objetivos pelas próprias ideias, medo de lugares ou situações de riscos (Wallach, 1993).

Percebe-se que a presença de agressividade referese não apenas a diferenças nos contextos sociais, mas também a diferentes faixas etárias e uma multiplicidade de condutas, independentemente de vulnerabilidades ou não. Entretanto, dentre as pesquisas estudadas não se observaram comparações de comportamentos agressivos entre delinquentes e pessoas bastante agressivas, mas sem antecedentes criminais conhecidos. Em razão disso, propôs-se estudar as diferenças de comportamentos declarados de pessoas com antecedentes criminais com universitários sem tais antecedentes.

\section{Participantes}

\section{Método}

Participaram desta pesquisa 83 sujeitos, divididos em dois grupos. O primeiro grupo (grupo 1) foi composto por 41 pessoas, que encontravam-se em regime de reclusão em uma instituição no inteiror do estado de São Paulo, de ambos os sexos, sendo 61\% com 18 anos e 39 \% com 19 anos de idade. Do total, $80,5 \%$ eram do sexo masculino. Todas as pessoas desse grupo tinham como características comuns histórico conhecido de prática de delitos (tráfico de drogas, assalto a mão armada e roubo de carro) quando menores de idade. Nenhum deles tinha 0 ensino fundamental completo.

O segundo grupo (grupo 2) foi composto por 42 participantes com altos índices de comportamentos agressivos declarados, avaliados por meio da Escala de Avaliação de Tendência à Agressividade, ou seja, que obtiveram maiores pontuações na escala. Esse grupo foi selecionado de um banco de 769 estudantes universitários dos cursos de humanas, exatas e biológicas de universidades do interior do estado de São Paulo e de Minas Gerais, sem histórico preinformado de possíveis delitos. Do total, 19\% eram do sexo feminino e $81 \%$ do sexo masculino. As idades desse grupo variaram entre 18 e 29 anos ( $M=23$ anos; $\mathrm{DP}=2,21$ ) e a distribuição das pessoas pelas idades entre 20-25 foi bem proporcional, sendo responsável por $80,5 \%$ dos participantes desse grupo.

\section{Instrumento}

A Escala de Avaliação de Tendência à Agressividade (Sisto, 2010) é constituída por 40 itens e fornece quatro medidas: uma delas se refere à avaliação das condutas mais comuns ao sexo masculino, outra às mais comuns ao sexo feminino, uma terceira é 
concernente a condutas comuns a ambos os sexos e, finalmente, uma é medida geral de tendência à agressividade. Possui evidência de validade por estrutura interna dos itens de duas naturezas diferentes, uma pelo funcionamento diferencial do item e outra por tipologias. Pode ser aplicada individual ou coletivamente e leva aproximadamente 15 minutos para ser respondida. O Manual (Sisto, 2010) relata coeficientes de precisão que variam de 0,81 a 0,94, os quais são considerados altos. Além disso, 0 instrumento apresenta evidência de validade por estrutura interna dos itens, funcionamento diferencial dos itens e pela tipologia. Trata-se de uma escala para adultos.

\section{Procedimento}

As instituições foram contatadas a fim de se solicitar autorização para a coleta de dados. Após a aprovação do projeto pelo Comitê de Ética da Universidade São Francisco, deu-se início à coleta de dados. As pessoas do grupo 1 responderam à escala individualmente, em sala especial, pois ainda estavam detidos esperando alvará de soltura. A aplicação no grupo 2 foi coletiva, em sala de aula. Em ambos os grupos a aplicação do instrumento foi feita após a assinatura do termo de consentimento livre e esclarecido. A duração total da aplicação foi aproximadamente 20 minutos, quando em sala de aula, e 25 minutos, quando aplicado individualmente.

\section{Resultados}

Primeiramente, será apresentado o mapa dos itens realizado pelo modelo de Rasch. Posteriormente, serão apresentados as médias desvio padrão de ambos os grupos. Em seguida, foi realizada uma análise de variância com controle da idade e do sexo. Por último, será apresentada uma análise com frequência igual a zero ou superior a $51 \%$. Para se ter uma visualização dos dois grupos estudados em termos de pessoas e itens, foi construída a Figura 1. Alguns dados chamam a atenção. Um deles se refere ao fato de que a média da pontuação das pessoas foi superior à média dos itens. Pela diferença ser muito pequena, esse dado pode ser indicativo de que a escala está bem ajustada para representar a tendência das pessoas. Esses dados podem ser visualizados nessa Tabela, onde a letra $\mathrm{M}$, ao lado da divisória das informações das pessoas e dos itens, indica a localização das médias, respectivamente.

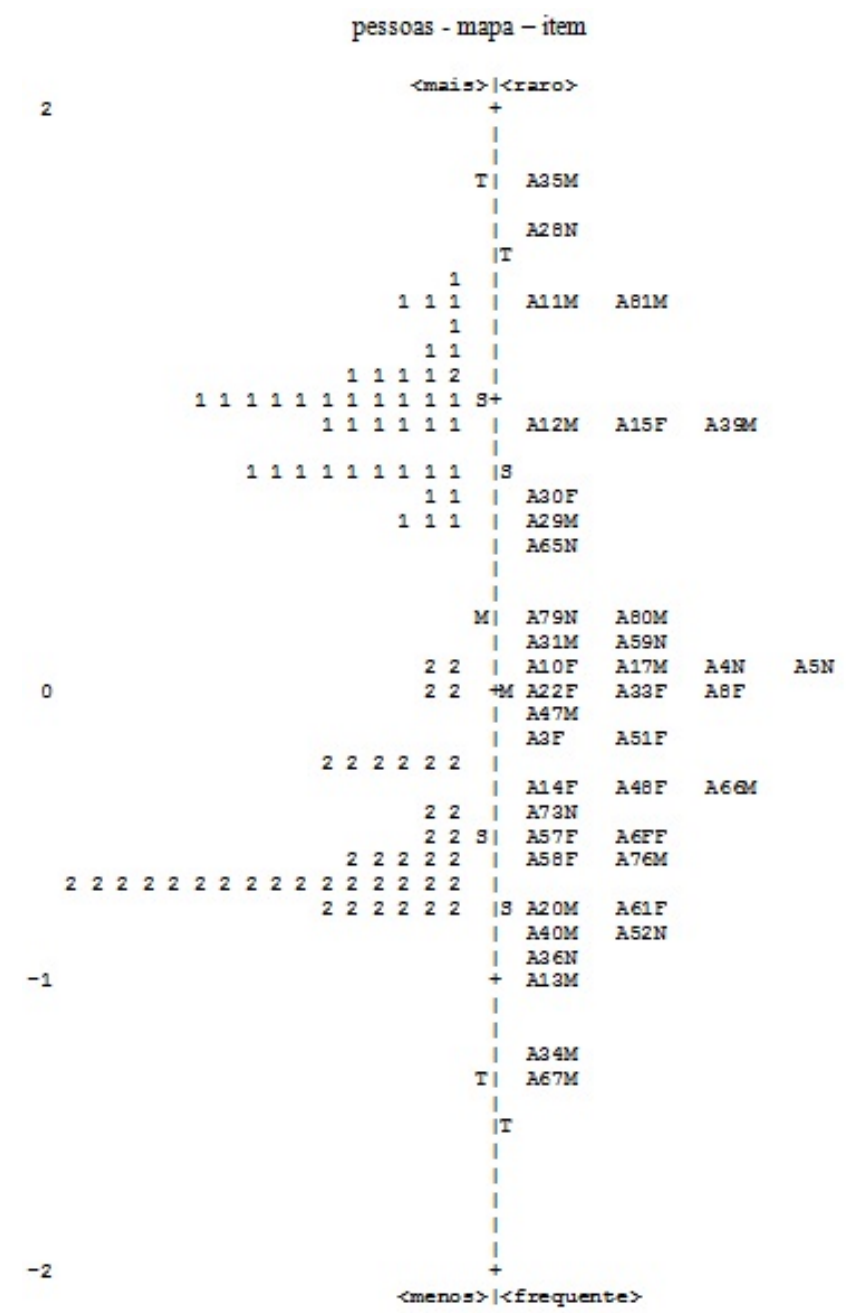

Figura 1. Mapa de itens e pessoas distribuídos em escala logit

A maioria dos itens se agrupou entre os valores +2 e -2 da escala logit, intervalo esse que avalia as pessoas com boa precisão e pouco erro. Finalmente, cabe ressaltar também que o grupo 1 , formado por pessoas com histórico de delinquência, ficou nitidamente destacado do grupo 2, formado pelos universitários com as maiores pontuações na EATA. Há uma única exceção, que é uma pessoa do grupo 2 que obteve pontuação no patamar das pessoas do grupo 1.

Pelas estatísticas descritivas de ambos os grupos um dos resultados que chama bastante a atenção é que as maiores diferenças se referem à pontuação mínima de cada grupo pesquisado (grupo $1=52$ e grupo $2=25$ ), enquanto os valores máximos mostraram discrepâncias menores (grupo 1=66 e grupo 2=61). Nesse caso, 0 grupo 1, constituído por pessoas que cometeram delitos antes dos 18 anos, forneceu valores mínimos muito superiores ao do grupo 2, formado pelos estudantes universitários com as maiores pontuações. 
Os dados do grupo 1 sugerem uma tendência em relação ao teto, no que tange ao EATA, apesar da curva mostrar uma leve tendência à normalidade, desprezando-se as baixas pontuações. No que concerne ao intervalo encontrado, ele variou entre 52-66, indicativo de que sua média $(58,51)$ ficou muito além do ponto médio da escala, pois esta variava entre zero e 80 pontos. Em relação às subescalas, todas as médias foram superiores aos seus pontos médios. Ao lado disso, mostraram uma leve tendência à curva normal.

Diferentemente, 0 grupo 2 mostrou uma tendência mais fraca à normalidade, mesmo tendo uma distribuição em intervalo maior. A esse respeito, as pontuações variaram entre 25-61, em uma escala de zero a 80 pontos. Como a média foi de 30,48, esse valor encontra-se abaixo do ponto médio da escala.

Nas subescalas referentes às tendências agressivas femininas (B) e masculinas (C) à normalidade se mostrou mais consistente que o EATA e na Subescala A no grupo 2, ainda que em nenhuma das situações tenha se definido como uma curva normal. Todas elas tiveram como médias valores inferiores aos pontos médios de cada subescala. A Tabela 1 oferece os dados descritivos (médias dos grupos e desvio padrão), por sexo.

Tabela 1. Média e desvio padrão em relação aos grupos e para as medidas de agressividade

\begin{tabular}{lccc}
\hline Agrsessividade & Grupo & Média & Desvio padrão \\
\hline EATA & 1 & 58,51 & 3,50 \\
& 2 & 30,48 & 7,00 \\
\hline Subescala A & 1 & 15,15 & 1,74 \\
& 2 & 6,38 & 2,68 \\
\hline Subescala B & 1 & 21,02 & 1,99 \\
& 2 & 11,85 & 3,88 \\
\hline Subescala C & 1 & 22,34 & 2,03 \\
& 2 & 12,24 & 5,53 \\
\hline
\end{tabular}

Esses dois grupos foram submetidos a uma análise de variância. Foram consideradas as subescalas, a escala como um todo (EATA), com controle do efeito das variáveis idade e sexo. Os resultados encontram-se na Tabela 2.

Por esses resultados, todas as medidas mostraram diferenças significativas entre os grupos. A tendência encontrada em todos os casos indicou que as maiores médias sempre foram as do grupo 1.
Com vistas a uma melhor especificação das diferenças entre os dois grupos, foram calculados os percentuais de cada intensidade de resposta para cada item da escala. A Tabela 3 facilita a visualização dos resultados, apenas com valores superiores a $51 \%$ ou iguais a zero. Como pode ser observado, 17 itens foram excluídos por esses dois critérios.

Tabela 2. Análise de variância das medidas por grupo, com controle do efeito das variáveis idade e sexo (continua)

\begin{tabular}{llcrrrr}
\hline \multirow{2}{*}{ Fontes } & Variáveis dependentes & $\begin{array}{c}\text { Type III } \\
\text { Soma dos quadrados }\end{array}$ & d & $\begin{array}{r}\text { Quadrado } \\
\text { médio }\end{array}$ & \multicolumn{1}{c}{$\mathrm{F}$} & $\mathrm{p}$ \\
\hline Modelo & Eorrigido & 16615,23 & 3 & 5538,41 & 199,52 & 0,000 \\
& SuTA & 1622,45 & 3 & 540,82 & 110,51 & 0,000 \\
& Subescala A & 1918,65 & 3 & 639,55 & 84,07 & 0,000 \\
& Subescala C & 2564,69 & 3 & 854,90 & 69,34 & 0,000 \\
\hline \multirow{2}{*}{ Intercepto } & EATA & 2243,92 & 1 & 2243,92 & 80,84 & 0,000 \\
& Subescala A & 146,68 & 1 & 146,68 & 29,97 & 0,000 \\
& Subescala B & 110,23 & 1 & 110,23 & 14,49 & 0,000 \\
& Subescala C & 613,06 & 1 & 613,06 & 49,73 & 0,000 \\
& EATA & 207,90 & 1 & 207,90 & 7,49 & 0,008 \\
iddade & Subescala A & 14,89 & 1 & 14,89 & 3,04 & 0,085 \\
& Subescala B & 4,45 & 1 & 4,45 & 0,59 & 0,447 \\
& Subescala C & 71,41 & 1 & 71,41 & 5,79 & 0,018 \\
\hline
\end{tabular}


Tabela 2. A nálise de variância das medidas por grupo, com controle do efeito das variáveis idade e sexo

\begin{tabular}{|c|c|c|c|c|c|c|}
\hline Fontes & Variáveis dependentes & $\begin{array}{c}\text { Type III } \\
\text { Soma dos quadrados }\end{array}$ & g & $\begin{array}{l}\text { Quadrado } \\
\text { médio }\end{array}$ & $\mathrm{F}$ & $\mathrm{p}$ \\
\hline \multirow[t]{4}{*}{ sexo } & EATA & 72,70 & 1 & 72,70 & 2,62 & 0,110 \\
\hline & Subescala A & 10,77 & 1 & 10,77 & 2,20 & 0,142 \\
\hline & Subescala B & 174,44 & 1 & 174,44 & 22,93 & 0,000 \\
\hline & Subescala C & 340,51 & 1 & 340,51 & 27,62 & 0,000 \\
\hline \multirow[t]{4}{*}{ grupos } & EATA & 4262,69 & 1 & 4262,69 & 153,56 & 0,000 \\
\hline & Subescala A & 438,21 & 1 & 438,21 & 89,54 & 0,000 \\
\hline & Subescala B & 546,26 & 1 & 546,26 & 71,80 & 0,000 \\
\hline & Subescala C & 440,32 & 1 & 440,32 & 35,72 & 0,000 \\
\hline \multirow[t]{4}{*}{ Erro } & EATA & 2192,99 & 79 & 27,76 & & \\
\hline & Subescala A & 386,61 & 79 & 4,89 & & \\
\hline & Subescala B & 601,01 & 79 & 7,61 & & \\
\hline & Subescala C & 973,96 & 79 & 12,33 & & \\
\hline \multirow[t]{4}{*}{ Total } & EATA & 181881 & 83 & & & \\
\hline & Subescala A & 11531 & 83 & & & \\
\hline & Subescala B & 24804 & 83 & & & \\
\hline & Subescala C & 28176 & 83 & & & \\
\hline \multirow[t]{4}{*}{ Total Corrigido } & EATA & 18808,22 & 82 & & & \\
\hline & Subescala A & 2009,06 & 82 & & & \\
\hline & Subescala B & 2519,663 & 82 & & & \\
\hline & Subescala C & 3538,651 & 82 & & & \\
\hline
\end{tabular}

Tabela 3. Itens selecionados por frequência zero ou superior a $51 \%$

\begin{tabular}{|c|c|c|c|c|c|c|}
\hline \multirow{2}{*}{ Item } & \multicolumn{3}{|c|}{ Grupo 1} & \multicolumn{3}{|c|}{ Grupo 2} \\
\hline & 0 & 1 & 2 & 0 & 1 & 2 \\
\hline 1 & & - & & - & - & 61,9 \\
\hline 2 & 0 & - & 70,7 & - & - & - \\
\hline 3 & 0 & - & 65,9 & - & - & 61,9 \\
\hline 4 & 0 & 51,2 & 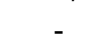 & - & - & - \\
\hline 5 & 0 & - & 75,6 & - & - & - \\
\hline 6 & 0 & - & 75,6 & - & - & - \\
\hline 7 & 0 & - & 80,5 & - & - & - \\
\hline 8 & 0 & - & 56,1 & - & - & - \\
\hline 9 & - & - & 80,5 & - & - & 71,4 \\
\hline 10 & - & - & 65,9 & - & - & 64,3 \\
\hline 11 & 0 & - & 65,9 & - & - & 64,3 \\
\hline 12 & 0 & 61,0 & & - & - & - \\
\hline 13 & 0 & 0 & 100,0 & - & - & - \\
\hline 14 & 0 & 0 & 100,0 & - & - & - \\
\hline 15 & 0 & 0 & 100,0 & - & - & - \\
\hline 16 & 0 & 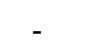 & 85,4 & - & - & - \\
\hline 17 & 0 & 0 & 100,0 & - & - & - \\
\hline 18 & 0 & 0 & 100,0 & - & - & - \\
\hline 19 & 0 & 0 & 100,0 & - & - & 64,3 \\
\hline 20 & 0 & 51,2 & 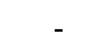 & - & - & - \\
\hline 21 & 0 & 0 & 100,0 & - & - & - \\
\hline 22 & 0 & - & 56,1 & - & - & - \\
\hline 23 & 0 & - & 56,1 & - & - & - \\
\hline
\end{tabular}


Alguns aspectos podem ser destacados dessa tabela. Deles, quatro serão ressaltados. Um deles refere-se ao fato de que apenas no grupo 1, referente às pessoas que cometeram delito, a intensidade 0-1 (nunca ou muito pouco) não foi marcada (frequência zero). Isso ocorreu em 21 dos 40 itens; além disso, deve-se acrescentar 0 fato de que em sete desses itens eles apareceram com 100\% na intensidade 2 (sempre). Desses sete itens, três deles concernem a condutas mais tipicamente femininas (Quando não gosto de alguém, sinto vontade de esconder a verdade para prejudicá-lo; Quando não gosto de alguém, sinto vontade de criar uma situação para desafiá-lo; Quando sinto raiva, tenho vontade de descontar em alguém); outros três se referem a condutas tipicamente masculinas (Se não tiver perigo de ser visto, entraria no cinema sem pagar; Relato sentimentos não-verdadeiros para iniciar um relacionamento sexual; Tenho vontade de andar armado) e, finalmente, um é comum a ambos os sexos (Quando faço algo errado, disfarço ou saio para não perceberem que fui eu).

O utro diz respeito a que nenhum item do grupo 2 teve frequência igual a zero nem a 100\% em nenhuma das intensidades. Porém, seis dos 40 itens forneceram frequências superiores a 51\%. D esses seis itens, quatro deles fazem parte da Subescala C, que contêm itens mais caracterizados como masculinos (Se não tiver perigo de ser visto, entraria no cinema sem pagar; Gosto de xavecar pessoas com menos de 18 anos; Gosto de correr com o carro; Dirijo após ingestão de bebida alcoólica), outro pertence à Subescala A (Gosto de demonstrar meus conhecimentos) e o último, à Subescala B (Altero o tom de voz quando não sou atendido ou entendido), relativo a condutas mais tipicamente femininas.

Em terceiro lugar, apenas uma conduta apareceu como nitidamente de grupo de universitários. Um percentual de 62,9\% assinalou com intensidade 2 (a mais alta) a conduta "Altero o tom de voz quando não sou atendido ou entendido", comportamento esse que não foi relatado como uma das condutas mais comuns ao grupo 1.

Finalmente, apenas quatro condutas foram comuns na maioria das pessoas pertencentes aos dois grupos. As condutas foram "Se não tiver perigo de ser visto, entraria no cinema sem pagar", "Dirijo após ingestão de bebida alcoólica”, "Gosto de correr com 0 carro", "Gosto de demonstrar meus conhecimentos", "G osto de xavecar pessoas com menos de 18 anos".

\section{Discussão e considerações finais}

No que tange ao desempenho geral dos indivíduos em relação aos itens da escala, os resultados mostraram ajuste adequado dos itens para as tendências agressivas das pessoas estudadas. Isso porque a média dos itens coincide com a média dos indivíduos. Nada obstante, o mapa dos itens e sujeitos deixa clara a diferenciação dos dois grupos, sendo que o grupo de delinquentes obteve as maiores pontuações na escala que o grupo de universitários altamente agressivos. Esses dados evidenciam boa precisão beneficiando a utilização dessa escala para a análise desse comportamento.

Os resultados mostraram que ambos os grupos 1 e 2 apresentaram pontuações mínimas acima do valor médio da EATA, evidenciando uma alta tendência para comportamentos agressivos. $\mathrm{Na}$ realidade isso era esperado devido às especificidades dos grupos, ou seja, 0 primeiro era composto por delinquentes e o segundo por universitários que obtiveram as mais altas pontuações na escala.

Todas as quatro medidas analisadas evidenciaram diferenças significativas entre os grupos, porém as maiores médias pertenceram ao grupo 1, indicando maiores tendências declaradas desses indivíduos para comportamentos agressivos. Entretanto, esses grupos não se diferenciaram por não apresentar um determinado comportamento, mas por declarar que os efetivavam em intensidades diferentes. Assim, a diferença não se fez presença nem tipo nem no comportamento, mas na intensidade de sua utilização.

Em relação ao desempenho dos sujeitos analisados nos itens, no que diz respeito ao grupo 2 (universitários) não houve frequência igual a 100\% em nenhuma das intensidades. Entretanto, em seis itens mais da metade das pessoas informaram executar esse comportamento. No que concerne à frequência de condutas, sete do total de itens apareceram com 100\% na intensidade sempre.

Dessas condutas mais intensas em ambos os grupos, apenas uma foi comum a eles, qual seja, "Se não tiver perigo de ser visto, entraria no cinema sem pagar". Descartando o critério de mais frequente e adotando do de frequência superior a $51 \%$, apenas quatro condutas foram comuns a ambos os grupos, e seus conteúdos são bastante diversificados, pois se referem a beber ou correr em situação de conduzir carro, a sexo e a mostrar conhecimentos. A respeito de beber ou correr em situação de conduzir carro, Virkkunen e Linnoila (1993) apontam uma associação entre criminalidade e o uso de álcool, e Murdoch e cols. (1990) concluíram que o álcool é copartícipe da criminalidade.

Concernente às diferenças entre os dois grupos, mas ainda referente a condutas relatadas com grande frequência, 0 que se pôde retirar dos dados foi 0 seguinte. 0 grupo 1 caracterizou-se por condutas 
relacionadas a enganar os outros para prejudicar, para obter sexo ou não perceberem minha culpa; desafiar pessoas, descarregar a raiva em alguém e andar armado. Por sua vez, ao grupo 2 lhe restou, das condutas mais frequentes e não comuns ao grupo 1, o fato de falar alto quando não atendido ou entendido (conhecido popularmente como "armar barraco").

Por fim, resta acrescentar que este estudo apresentou uma dificuldade para sua realização, que necessita ser ressaltada. Não foi possível encontrar um grupo de pessoas de 18-19 anos com altos níveis de agressividade, sem histórico policial e com escolaridade similar ao outro grupo. A solução encontrada foi estudar pessoas cuja média de idade era bem maior e depois controlar o efeito da idade na análise dos dados. Entretanto, por mais que esse seja um procedimento válido estatisticamente, sabe-se que 0 fenômeno agressividade tem um pico de ocorrência por volta dos 18 anos (D onker, Smeenk, van der Laan \& Verhulst, 2003; Hirschi \& Gottfredson, 1995), e depois há uma diminuição (Blumstein \& Cohen, 1987), o que foi por alguns pesquisadores interpretado como uma característica desenvolvimental (Krueger \& cols., 1994; Pearlin \& cols., 1981: Sisto, 2010). Também é necessário considerar as diferenças de escolaridade entre os grupos, elemento esse não controlado estatisticamente, pois não mensurável em suas qualidades. Nesse contexto, os resultados e discussões devem ser considerados com ressalvas e mais como uma contribuição inicial ao estudo dessa problemática. Ainda, pode-se afirma que o objetivo desta pesquisa foi atingido, haja vista terem sido encontrados diferentes comportamentos entre delinquentes e universitários, e, além disso, a escala utilizada foi capaz de separar ambos os grupos. Espera-se que novas pesquisas envolvendo a agressividade juvenil e do adulto jovem sejam desenvolvidas, oferecendo subsídios para novos trabalhos e proporcionando aumento no acervo referente a essa temática. Algo de que se sentiu bastante falta na literatura foi a descrição de condutas agressivas das pessoas, ou seja, quais são os comportamentos utilizados por pessoas agressivas, e ainda a diferenciação de pessoas altamente agressivas, porém sem histórico de delito, e de delinquentes. No geral, descreve-se uma situação tipicamente agressiva e ela é estudada, mas outras condutas correlatas e concomitantes a ela são muito pouco exploradas, como por exemplo, a utilização de mentiras para obter vantagens sexuais que é um tema estudado apenas na patologia e não em toda sua compreensão e âmbito que a cerca.

\section{Referências}

Anderson, C. A., \& Bushman, B. J. (2002). Human aggression. Anmual Reviewof Psychdogy, 53, 27-51.

Baumeister, R. F., Smart, L., \& Boden, J. M. (1996). Relation of threatened egotism to violence and aggression: the dark side of high self-esteem. Psychdogial Reviev 103, 5-33.

Berkowitz, L. (1990). On the formation and regulation of anger and aggression: a cognitiveneoassociationistic analysis. Ammican Psydhdogist, 45, 494-503.

Berkowitz, L. (1993). Pain and aggression: some findings and implications. Motivation and Emotion, 17, 277-293.

Blumstein, A., \& Cohen, J. (1987). Characterizing criminal careers. Säence, 237, 985-991.

Bushman, B. J., \& Baumeister, R. F. (1998). Threatened egotism, narcissism, self-esteem, and direct and displaced aggression: does self-love or self-hate lead to violence? Jaumal of Pesonality and Social Psychology, 75, 219-29.

Check, J. V. P., Malamuth, N. M., Elias, B., \& Barton, S. (1985). On hostile ground. Psychdogy Today, 19, 56-61.

Dill, K. E., Anderson, C. A., Anderson, K. B., \& Deuser, W. E. (1997). Effects of aggressive personality on social expectations and social perceptions. Jaumal of Reserch in Pesonality, 31, 272-292.

D onker, A. G., Smeenk, W. H., van der Laan, P. H., \& Verhulst, F. C. (2003). Individual stability of antisocial behavior from childhood to adulthood: testing the stability postulate of moffitt's developmental theory. Cinindogy, 41(3), 593-609.

Geen, R. G. (2001). Human aggession (2 $2^{\mathrm{a}}$ ed.). Londres: Taylor \& Francis.

Gomà-i-Freixanet, M. (1995). Prosocial and antisocial aspects of personality. Pessmality and Indvidual Differences, 19, 125-134.

Grisci, C. L. I. (1991). Relações entre acidentes de trânsito e as variáveis de agressividade, atuação e culpa. Psico, 2(1), 103-117.

Hirschi, T., \& Gottfredson, M. R. (1995). Control theory and the life-course perspective. Studies on Crime\& CinmePrevention, 4, 159-175.

Huesmann, L. R., Eron, L. D ., \& D ubow, E. F. (2002). Childhood predictors of adult criminality: are all 
risk factors reflected in childhood aggressiveness? Criminal behaviaur andMental Helth, 12, 185-208.

Huesmann, L. R., \& Guerra, N. G. (1997). Children's normative beliefs about aggression and aggressive behavior. Jauml of Pessonality and Sccial Psychdogy, 72, 408-419.

Kernis, M. H., Grannemann, B. D., \& Barclay, L. C. (1989). Stability and level of self-esteem as predictors of anger arousal and hostility. Jarmal of Personalityand Social Psychdogy, 56, 1013-1022.

Krueger, R. F., Schmutte, P. S., Caspi, A., Moffitt, T. E., Campbell, K., \& Silva, P. A. (1994). Personality traits are linked to crime among men and women: evidence from a birth cohort. Jaumal of Alonomal Psydholog, 103, 328-338.

Lippa, R. A. (1990). Introduction to soial psydhdogy. Belmont, CA: Wadsworth.

Lipsitt, L. P. (Org.). (1990). Videne and aggession in addesence The Brown University Child Behavior and D evelopment Letter.

Lisak, D., \& Roth, S. (1990). Motives and psychodynamics of self-reported, unincarcerated rapists. Ameican Jamal of Orthopsychiatry, 60, 268280.

Lish, J. D., Kavoussi, R. J., \& Coccaro, E. F. (1996). Aggressiveness. Em C. G. Costello (O rg.), Pessonality dharacteistics of the personality disardeed (pp. 24-40). Nova Iorque: Wiley.

Murdoch, D., Pihl, R. O., \& Ross, D. (1990) Alcohol and crimes of violence: present issues. Intemational Jamal of theAddicions, 25, 1065-1081.

Myers, J. (1993). Social psydhdog. Nova Iorque: McGraw-Hill.

Patterson, G. R., DeBaryshe, B. D., \& Ramsey, E. (1989). A developmental perspective on antisocial behavior. American Psychdogist, 44, 329-335.
Pearlin, L. I., Menaghan, E. G., Lieberman, M. A., \& Mullan, J. T. (1981). The stress process. Jaumal of Healthand Soial Behavior, 22(4), 337-356.

Pulkkinen, L., Virtanen, T., Klinteberg, B. A., \& Magnusson, D. (2000). Child behaviour and adult personality: comparisons between criminality groups in Finland and Sweden. Criminal Behaviar and Mental Heelth, 10, 155-169.

Raine, A. (1993). The psychopathdogy of cime ciminal bahavior as a dinical dsarder. San D iego: Academic Press.

Raine, A., Reynolds, C., Venables, P. H., Mednick, S. A., \& Farrington, D. P. (1998). Fearlessness, stimulation-seeking, and large body size at age 3 years as early predispositions to childhood aggression at age 11 years. Archives of General Psychiatry, 55, 745-751.

Sisto, F. F. (2003). Rejeição entre colegas e agressividade na infância. Cadkmos dePsicogà, 13, 83-98.

Sisto, F. F. (2010). Escala de Avaliação de Tendênia a Agressividade São Paulo: Casa do Psicólogo.

Sposito, M. P. (2001). Um breve balanço da pesquisa sobre violência escolar no Brasil. Eduração e Pesquisa, 27(1), 87-103.

Virkkunen, M., \& Linnoila, M. (1993). Brain serotonin, type II alcoholism and impulsive violence. Jamal of StudiesonAlchd Supplement, 11, 163-169.

Wallach, L. B. (1993). Helping children cope with violence. YaungChildren, 48(4), 4-11. 
Sobre os autores:

Fermino Femandes Sisto é doutor pela Universidad Complutense de Madrid, livre-docente e professor titular aposentado pela Unicamp e docente do curso de Psicologia e do Programa Pós-Graduação em Psicologia da Universidade São Francisco. Foi assessor da Comissão de Avaliação de Programas de Pós-G raduação em Psicologia da CAPES. Bolsista de Produtividade em Pesquisa 1B.

Femando José Silveira é psicólogo com especialização em Neuropsicologia pelo CEPSIC - HVFMUSP. Mestre em Psicologia pela Universidade São Francisco e doutorando em Psicologia pela Universidade São Francisco. Atua como psicólogo e neuropsicólogo clínico e é professor da UNIFENAS e do Instituto ENAF de Pós-Graduação.

Dario Cecilio-Femandes é psicólogo formado pela Universidade São Francisco. Atualmente é mestrando em Psicologia pela Universidade São Francisco e bolsista CNPq.

Contato com os autores:

Universidade São Francisco. Rua Alexandre Rodrigues Barbosa, 45 - Itatiba-SP.

E-mail: fermino.sisto@gmail.com 